\title{
Evaluating the Impact of Factors on Young Cyclists' Intention of Aberrant Crossing at Intersections in China Based on Theory of Planned Behavior
}

\author{
Yuan Zheng \\ 1Jiangsu Key Laboratory of Urban ITS, Southeast \\ University \\ 2Jiangsu Province Collaborative Innovation Center of \\ Modern Urban Traffic Technologies \\ Si Pai Lou \#2, Nanjing, China, 210096 \\ Email:seuzhengy@163.com
}

\author{
Guoqiang Zhang \\ 1Jiangsu Key Laboratory of Urban ITS, Southeast \\ University \\ 2Jiangsu Province Collaborative Innovation Center of \\ Modern Urban Traffic Technologies \\ Si Pai Lou \#2, Nanjing, China, 210096 \\ Email: guoqiang.zhang@163.com
}

\begin{abstract}
This paper evaluated the impacts of various factors on the youngcyclist's intention of aberrant crossing behaviors at intersections. Bicycles were classified into conventional bikes and electric bikes (hereinafter referred to as e-bikes). Data were collected from 374 participants in Nanjing, China.The hierarchical multiple linear regressionanalysis was conducted to estimate the impacts of various factor variablesbased on the theory of planned behavior (TPB). The results showed that three key traditional TPB variables including attitudes, subjective norm, perceived behavioral control (PBC) accounted for 50\% of all variances in two scenarios plus the variables of past behavior with $3 \%$ of variance, conformity tendency in bikes scenario and anticipated affect with $1 \%$ of variance in e-bikes scenario constituting two modified TPB model. Three key traditional TPB variablesresulted in an abundant increase of $42 \%$ of thevariance in e-bikes, which is $6 \%$ higher than that in another scenario. The allselected predicting variables accounted for $66 \%$ of variance for e-bikes and $60 \%$ for bikes in predicting the crossing intentions. The findings of this study can help come up with interventions and educations measures for aberrant crossing behaviors based on the effect analysis of variables on intention.
\end{abstract}

KEYWORDS-aberrant crossing intention;Theory of Planned Behavior;variables;conventional bikes and electric bikes; comparison

\section{INTRODUCTION}

The problem of traffic congestion and air pollution from motor vehicles has raised growing concerns in urban transportation planning and management. As a complement to vehicular traffic, non-motorized travel modes (e.g. walking, cycling) have been promoted to better create a liveable and sustainable urban transportation system. Electric bike (e-bike), as a convenient and economical transportation mode, is often considered as a preferred choice among urban residents with respect to travel mode determination. Without the high expense of taxi and the low travel comfort experience of bicycle as well as some public transit modes, e-bikes possesses noticeable advantages in balancing individuals' mobility and accessibility patterns [1]. In addition, the usage of e-bikes could also bring some environmental benefits. For instance, e-bikeswere found to have a much lower polluting emission comparing to motorcycle and car [2]. Therefore, in the past few decades, there is a growing popularity of e-bikes usage especially among urban residents in cities with crowdedpopulation density. According to the information from China Bicycle Industry Information Center in 2013, the predicted ownership of e-bikes in China is about 130 million and the expected annual growth rate remains at 4 percent between 2013 and 2020.

Despite the fact that the increase in e-bikesusage as a regular travel mode has brought considerable benefits from both individual and environmental prospects, the following consequences such as traffic operational influences (e.g. traffic chaos) and traffic safety impacts (e.g. e-bikes accidents) deserve special attentions. The number ofe-bikersrelated fatalities and injuries has increased significantly over the past few years. Furthermore, fatalitiesand injuries of e-bikers accounted for $28.8 \%$ and $54.1 \%$ of thenon-motorized traffic fatalities and injuries in China, $2010[3,4]$. Accident analysis revealed that over $60 \%$ of cyclists involvingfatal crashesresulted from the violation of traffic rules, such as aberrant behaviors of running red light, speeding, overloading etc. In many cases, crashes between non-motor vehicles and vehicles often arise from cyclists' distracted decisions or risky behaviors during their road crossings processes. One typical violation behavior is that cyclists with either e-bikers (1) or bikers (2) (an exampleis shown in Fig.1) continue to runduring red light phase at signalized intersections. Because of the ineffective enforcement of traffic laws and the weak safety awareness of traffic participants, violations in urban intersections are rather prevalent and become a research direction in traffic safety area. 


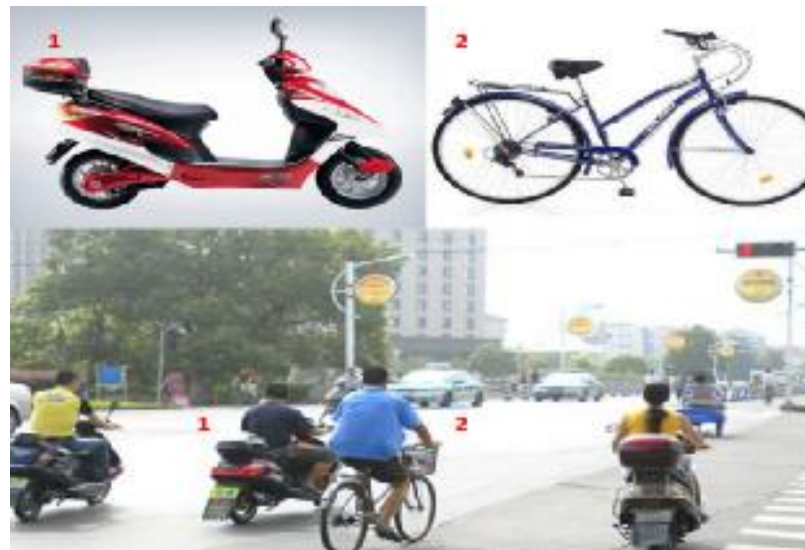

Figure1.Aberrant Behavior of E-bikes and Bikes at Intersection.

Previous studies have provided valuable insights into the internal characteristics of bicycle operations as well as theexternalfactors that influence cyclists' riding behaviors. Plenty of researcheshave focused on examiningfactors that influence e-bikers' aberrant road crossing behaviors[5], includingphysical environment (e.g. road width, type of street, etc.), road user variables (e.g.demographiccharacteristics such as physiological and psychological factors) and e-bike elements (e.g. character of service, traffic characteristics).

In addition, some of these researches on the influencing factors of bikers' riding behaviors have been done in the last decades. And these researches could be generally divided into seven research topics: bikes and cyclists' characteristics, traffic flow, intersection control, capacity and level of service, geometric design etc.A detailed classification and illustration of these influence variables of e-bike studies can be derived from Taylor [6].

Further, massiveconflicts caused by aberrant behavior of crossing betweennon-motor vehicles and vehicleswere analyzed. Traffic conflicts techniques were used to estimatethe safety effects of e-bikes and bikes and a comparison between them was conducted to judge if the conflicts from e-bikeswere more likely to cause accidents[4].

These studies provide valuable insights inunderstanding the factor that possibly leading to the aberrant behavior of road crossing and afterwards conflict analysis caused by the violated behaviors of e-bikesand bikes cyclists in China. And more studies on riding behaviors were conducted through analyzing the influence factors of userbehaviors' intention since these factors were found to be the primary determinant of traffic safety [7].

On the other hand, the relevant psychological factors are also needed to improve cyclists'safety. However, few research efforts have been contributed to estimate the aberrant riding behaviorsand their associated psychological factors of cyclists.

One such model, the Theory of Planned Behavior (TPB) proposed by Ajzenhasbeen widely adopted within the field of traffic safety [8]. And somewell-known studies have applied TPB asthe way of investigating and examining decision making inroad crossing situations from psychological aspect of drivers and cyclists.With regard to the traditionalTPB, an individual's intention canbe predictive of actual behavior when performing a particular mannerand it is determined by one's attitude toward the behavior in question, subjectivenorms andperceived behavioral control (PBC). For example,in addition to the basic variablesof TPB, newly discovered variables such as moral norms, anticipated regret, past behavior, self-identityand perceivedsusceptibility were applied to predict motorcyclists'intention to ride over the speedlimit[9]. Yao and $\mathrm{Wu}$ identified risk factors affecting the accident involvement of e-bikers and established the relationships between safety attitude, riskperception, and aberrant riding behaviors [7]. Zhou set questionnairesto measure people'sintentions when crossingan intersection in two road crossing situations, and their modified TPB model were consist of the attitude, subjective norms, PBC, anticipated affect, moral norms, and perceivedrisk [10].

However,few attempts havebeen made to relate aberrant behavior of crossing to potentiallymotivational variables through established theoretical TPB model.Further, few studies haveassessed the predictive utility of the modified model with respect to aberrantcrossing.

Given that most of previous studies have demonstratedthe impact of additional variables on intentions and behavior, even after the traditional TPB variables have been taken into account the present study to test an extended TPB model[11]. For example, previous researches on the behaviors of driver and pedestrianalso pointedout that several variables can be extended in the traditional TPB model. Several studiesexamined the difference of gender and age on pedestrians' behavior[12]. Cycling experience was also citedas one of the major influence factors, with a significant numberof motorcycling accidents occurring within the first six monthsof motorcycle riding [13]. Chorltonidentified a diversity of variables such as age and training status which were found to have an influence on motorcycle accident risk and severity [9].

Studies have shown that moral norm have an important influence on motorcyclists'decision to speed up when added to the predictionof speed intentions [14] andobserved speeding behaviors[15]. Self-identitycharacterized by one'sself-identification for safe behavior, has been shown topredict pedestrians' road crossing intentions and conformity tendency could emerge as the significant predictor of intention to road crossing for pedestrians [10]. Past behavior is typically the strongest predictorof intention and behavior, explaining variance over that accounted for by the TPB variables [16]. Perceived risk was measured by thestatements [9]. Some studies havealso examined the anticipated affect after having crossedthe intersection as depicted by [17].

So far, little studieshave applied the TPB to explore the impact of intentionson cyclists' behaviors with e-bikes or bikes of road crossing inChina. Moreover, few researches have focused on cyclists' aberrant behaviors of road crossingat intersections. Therefore, this researchis intended to fill this knowledge gap. The focus on young cyclistswhoare willing to have the aberrant behavior of road crossing is a concern, which is in line with the study from Shankar [18]. Therefore, the primary objectives of this study are as follows: 
(1) extend the traditional TPB model on aberrant intention of crossing intersection for e-bikers and bikersgiven the increasing number of studies that have provedthe impact of additional variables on intentions and integrate these different variablesintothemodified TPB model for scenariosin Nanjing, China.

(2) explain the extent to which the modified TPB model are impactedby demographic andother additional variables (i.e., conformity tendency, moral norm, anticipated affect, pastbehavior, self-identity, control beliefetc.) on cyclists' road crossing intentions in each scenario.

(3) access the predictive utility of the modified model in both scenarios and analyze the comparative effect of the modified TPB model and impacts of factor variables are compared between e-bikes and bikes situation.

\section{DATA COLLECTION}

\section{A. Participants}

A total number of 344cyclists, aged from 18-30 years old, responded to the survey. All participants were selected fromthe urban residents dwelling at the central areas in Nanjing. The samples were approximatelybalanced by gender on the whole. A pre-designed questionnaire was delivered to eachparticipant at a public place such as a supermarket or a fast food restaurant. So the sample randomly selected from resident cyclistsgroup in Nanjing. All participants were asked to read an introduction about the research and the format of the questionnaires beforefilling in the items. And an informed consent form was also assigned to each participant to ensure information security and privacy protection. Respondentswere ensured that participants were voluntary and their responses would be valid for the later analysis. Inaddition 18 questionnaires were excluded for the analysis because they did not answer the items in questionnaires completely.

\section{B. Questionnaire}

Generally, electric bikes can be divided into two categories: scooter style electric bikes (SSEB) and bicycle style electric bikes (BSEB) [19]. But two cycling modes were generated in this study: one was cycling e-bikes including above two categories, and the other was cycling bikes.

In the questionnaire, participants would like to rate on 7-point Likert Scales, including depiction of the likelihood degree that they would cross intersection with aberrant behaviors in two situations. Meanwhile, the perceived degree of aberrant road crossing in two situationswas obtained from some question items, thus to get their overall rating of each item selected.

Participants in the study were asked to fill out a questionnaire selecting one from two modes: e-bikes and bikes scenario. Then participants completed to a seriesof items constructed (e.g., age, gender, etc.), then standard TPB variables (attitude, subjective norm, PBC)and additional variables (anticipated affect, control belief, etc.) consisted of items in questionnaires. The dimensions number of factors categorized by items in this research was eleven satisfied to anticipated result and at last toward the stabilization on this number. Finally this paper included six additional variables: control belief, moral norms, anticipated affect, pastbehavior, self-identity and perceived risk, conformity tendency.

\section{METHOD}

Exploratory Factor Analysis (EFA) method was used to find the underlying dimensions that influenced the questionnaire variables. The EFA process adopted the principal component andvarimax rotation approach. First of all, the collected data should be distinguished weather to have a factor analysisusing Kaiser-Meyer-Olkin and Barrfett spherical inspection coefficient. Then factor analysis would be carried out when the coefficient was more than 0.70 [20].

The research also needed to conduct the reliability and validity analysis to ensure the responsibility of questionnaires and quality of items.Generally Cronbach's alpha, a coefficient of consistency that measured thehomogeneity of items in a dimension, was used to evaluate the reliability andinternal consistency. Following Nunnally's criteria, alpha values equal to or exceed 0.7 indicatedthe acceptablereliability [21].

Validity was used to measure the difference degree between result and the anticipated goal. Then validity was analyzed by using the criterions listed as follows: (1) loading value of each itemon the common factor that was at least more than 0.40 ; (2) each item did not exist the crossing-loading, namely two or more loading value with more than 0.40 on one common factor was invalid; (3) degree of communality was not less than 0.16 . The items that did not satisfy the three criterions were rejected through screening analysis from several steps.

\section{RESULT}

A series of hierarchical multiple linear regression analyzes were applied to assessthe contribution of variables for each scenario. It was likely to analyze the predictive utility of each variableafter controlling other influencevariables from table 1.

Consideringe-bike situation, in Step (1), age, gender, marital status and independent childrenaccount for $9 \%$ of thevariance in behavioral intentions (F-change $(4,166)$ $=4.06, \mathrm{p}<0.001)$, withall four variables emerging as significant predictors. In Step (2), riding variablesaccount for an additional $10 \%$ of thevariance in intentions (F-change $(5,161)=7.98, p<0.001)$, withall five variables emerging as significant predictors.In Step (3), thetraditional TPB variables, when added to the regression analysis, account for an additional $42 \%$ of variance, resulting in asubstantial and significant increment to $61 \%$ in intention $(\mathrm{F}$-change $(3,158)=65.37, \mathrm{p}<0.001)$, with three TPB variables emerging assignificant predictors along with demographic and riding variables. In Step (4), the extendedtraditional TPB variables only account for an additional $2 \%$ of variance in roadcrossing intention (F-change $(1,157)=69.86, \mathrm{p}<0.05)$. In Step (5), the five extended TPB variables only account for anadditional 3\% of the variance in intention $(\mathrm{F}$-change $(5,152)=72.38$, $\mathrm{p}<0.05)$, so that all fiveextended variables emerging as slightly significant predictors. In Step (6), extended variables of anticipated affectaccount for an additional $1 \%$ of variance in intention (F-change $(1,151)=75.43, p<0.05)$, with anticipated affect havinga small but statistically significant independent effect alongwith others' variables. 
For bike situation, in Step (1), age, gender, marital status and independent childrenaccount for $4 \%$ of thevariance in behavioral intentions (F-change $(4,168)$ $=1.91, \mathrm{p}>0.05)$, withall three variables emerging as insignificant predictors. In Step (2), riding variablesaccount for anadditional $6 \%$ of thevariance in intention $(\mathrm{F}$-change $(5,163)=4.03, \mathrm{p}<0.05)$, withall five variables emerging as slightly significant predictors.In Step (3), thetraditional TPB variables, when added to the regression analysis, account for an additional $36 \%$ of the variance, resulting in increment to $46 \%$ in intention (F-change $(3,160)=39.65, \quad \mathrm{p}<0.001)$, with three TPB variables emerging as most significant predictors. In Step
(4), the extendedtraditional TPB variables account for an additional $2 \%$ of the variance in intention (F-change $(1,159)$ $=44.94, \mathrm{p}<0.05)$. In Step (5), the five extended TPB variables account for anadditional $9 \%$ of the variance in intention $(\mathrm{F}$-change $(5,154)=50.98, \mathrm{p}<0.001)$, so that all fiveextended variables emerging as significant predictors than five variables in another situation. In Step (6), extended variables of anticipated affectaccount for an additional $3 \%$ of the variance in intention (F-change $(1,153)$ $=63.27, \mathrm{p}<0.001$ ), with past behavior havinga relatively large but statistically significant effect alongwith others' variables.

\begin{tabular}{|c|c|c|c|c|c|c|c|c|c|c|}
\hline Step & Predictor & $\mathbf{R}^{2}$ & $\Delta \mathbf{R}^{2}$ & $\mathbf{F}$ & Step 1 & Step 2 & Step 3 & Step 4 & Step 5 & Step 6 \\
\hline & E-bikes & & & & & & & & & \\
\hline \multirow[t]{4}{*}{1.} & Gender & .09 & .09 & 4.06 & .00 & -.05 & .02 & .02 & .02 & .01 \\
\hline & Age & & & & .09 & .16 & .13 & .11 & .08 & .08 \\
\hline & Marital status & & & & -.17 & -.18 & -.06 & -.03 & -.05 & -.05 \\
\hline & Dependent children & & & & $.44 * * *$ & $.38 * * *$ & $.19^{*}$ & .15 & $.18^{* *}$ & $.19 * *$ \\
\hline \multirow[t]{5}{*}{2.} & Frequency & .19 & .10 & 7.98 & & -.11 & .01 & .02 & .03 & .05 \\
\hline & Riding Experience & & & & & -.04 & -.02 & -.03 & -.01 & -.01 \\
\hline & Accident history & & & & & $-.20 * *$ & -.05 & -.06 & -.10 & -.09 \\
\hline & License status & & & & & $.17 * *$ & .10 & .10 & .10 & .09 \\
\hline & Driving Experience & & & & & -.10 & .04 & .06 & .06 & .07 \\
\hline \multirow[t]{3}{*}{3.} & Attitude. & .61 & .42 & 65.37 & & & $.33 * * *$ & $.31 * * *$ & $.26^{* * *}$ & $.26^{* * *}$ \\
\hline & Subjective norm & & & & & & $.32 * * *$ & $.31 * * *$ & $.21 * * *$ & $.21 * * *$ \\
\hline & $\begin{array}{l}\text { Perceived behavioral } \\
\text { control }\end{array}$ & & & & & & $.23 * * *$ & $.20 * *$ & $.16^{* *}$ & $.15^{*}$ \\
\hline 4. & Control belief & .62 & .01 & 69.86 & & & & $.13 * *$ & $.12 *$ & .12 \\
\hline \multirow[t]{5}{*}{5.} & Moral norm & .65 & .03 & 72.38 & & & & & -.04 & -.04 \\
\hline & Past behavior & & & & & & & & $.17 * *$ & .09 \\
\hline & Perceived risk & & & & & & & & -.08 & -.08 \\
\hline & Self-identity & & & & & & & & -.00 & .01 \\
\hline & Conformity tendency & & & & & & & & $.13 *$ & .11 \\
\hline \multirow[t]{2}{*}{6.} & Anticipated affect & .66 & .01 & 75.43 & & & & & & $.14^{*}$ \\
\hline & Bikes & & & & & & & & & \\
\hline \multirow[t]{4}{*}{1.} & Gender & .04 & .04 & 1.91 & -.08 & -.06 & -.02 & -.04 & .01 & .02 \\
\hline & Age & & & & .16 & .16 & .12 & .13 & .06 & .08 \\
\hline & Marital status & & & & .13 & .22 & .17 & .15 & .07 & .09 \\
\hline & Dependent children & & & & .13 & .10 & -.04 & -.02 & -.06 & -.09 \\
\hline \multirow[t]{5}{*}{2.} & Frequency & .10 & .06 & 4.03 & & .11 & .11 & .10 & $.14 *$ & $.13^{*}$ \\
\hline & Riding Experience & & & & & .05 & .02 & .01 & .02 & -.03 \\
\hline & Accident history & & & & & $-.20 * *$ & -.08 & -.07 & -.02 & -.02 \\
\hline & License status & & & & & -.04 & -.06 & -.07 & $-.12 *$ & -.10 \\
\hline & Driving Experience & & & & & -.08 & -.12 & -.12 & $-.17 * *$ & $-.14 *$ \\
\hline \multirow[t]{3}{*}{3.} & Attitude. & .46 & .36 & 39.65 & & & $.37 * * *$ & $.32 * * *$ & $.25 * * *$ & $.21^{* * *}$ \\
\hline & Subjective norm & & & & & & $.23 * * *$ & $.17 * * *$ & $.15^{* * *}$ & $.13^{* * *}$ \\
\hline & $\begin{array}{l}\text { Perceived behavioral } \\
\text { control }\end{array}$ & & & & & & $.28 * * *$ & $.24 * * *$ & $.21 * *$ & $.20 * * *$ \\
\hline 4. & Control belief & .48 & .02 & 44.94 & & & & $.15^{* * *}$ & $.13 * *$ & .10 \\
\hline \multirow[t]{5}{*}{5.} & Moral norm & .57 & .09 & 50.98 & & & & & $-.15 *$ & -.12 \\
\hline & Anticipated affect & & & & & & & & .11 & .07 \\
\hline & Perceived risk & & & & & & & & .01 & -.04 \\
\hline & Self-identity & & & & & & & & -.02 & -.01 \\
\hline & Conformity tendency & & & & & & & & $.26 * * *$ & $.18^{* * *}$ \\
\hline .6 & Past behavior & .60 & .03 & 63.27 & & & & & & $.26^{* * *}$ \\
\hline
\end{tabular}

Note: All correlation coefficients is $* * * p<0.001,{ }^{* *} \mathrm{p}<0.01,{ }^{*} \mathrm{p}<0.05$. 


\section{DISCUSSION}

The results demonstrate that all predictor variables accounts for $66 \%$ in e-bikes and $60 \%$ in bikes scenario of thevariance in predicting intentions which is consistent with reviews of the TPB with even taking account of additional variables remaining below $50 \%$ on average [10].

\section{A. Support for the traditional TPB variables}

In general, the findings indicate strongly supports for the applicationof the TPB to cyclists' intention.In line with previous studies [17], the overall results illustrate the usefulnessof attitude, subjective normand PBC assignificant predictors of behavioral intention in bothscenarios.

The standardized beta weights of three traditional TPB variables were positive for all modelsand demonstrated that as attitudes and subjectivenorms regarding the crossing behavior become more positive and PBC increased, people are more likelyto present stronger intentions to cross the intersection. As can be seen fromthe models in both situations, these basic traditional TPB variables aregenerally far more important predictors and they accounted for more than $50 \%$ of the change variance, in accordance with the study [9].

\section{B. No support for the extended traditionalTPB variables}

Analysis variable of PBC highlights in bikes than e-bikes situation when the control belief does not enter or enter the regression model. Yet control belief with low coefficient does not emerge as significant predictor in both situations. Hence it means that control belief has not effect on the contribution of $\mathrm{PBC}$ in the regression model, which represents $\mathrm{PBC}$ and control beliefs not emerging as significant predictors simultaneously is in line with the study [9].

\section{Support for the extended TPB variables constituting the modified TPB model}

In line with Zhou'sstudy, moral norm is not a significant predictor of crossing intentions [10]. Anticipatedaffect, emerges as a significant predictor forroadcrossing intention in e-bikes situation, while it is not of such significance in bikes situation. This result could possibly arise from the fact that e-bikes own the feature of traveling at a faster speed than bikes leading to more potential opportunities to cross the intersection. Thus, e-bikers focus on the expressive anticipated feelings so as to decide whether or not to violate the traffic regulations in road crossing processes. And Lin demonstrated that the mean operating speed of e-bikes was found to be $47.6 \%$ higher than that ofbikes [22]. So the speed difference between e-bikes and bikes may be the discriminative factor variables to the different modified model.

Indeed, evidenceregarding the predictive utility of perceived risk has been somewhat mixed througha broader literature. The result isinconsistent with Chorlton's study in that perceived riskis not a significant predictor for two situations in our study [9]. There are possibly underlying factors, such as optimistic biasor unrealistic optimism related to theidea that individual rider felt less risk than others are to increase disease ordanger [23]. Thus perceived risk may not have effect on intentions if therelevant risk is not understood. The finding is identical to study from Norman's study [17]. In contrastto the study by Chorlton, past behavioris significant for predicting intention to road crossing when added to othervariablesand it is the most important variable among the extended variables in bikes situation [9]. However, past behaviorcannot be regarded as a significant variable, though it can be emerged as a significant predictor when anticipated affect did not enter the model in e-bikes situation.

Therefore, results from this study along with findings fromprevious studies, suggest that past behavior and anticipated affect may be a significantpredictor for roadcrossing intentions in different scenario and perceived risk, self-identity, moral norm may require more investigation. Conformity tendency is a significant predictor for bikes situation, not for e-bikes situation. It is also possible that other factors, given individual bikers with a tendency towards conformitywould be more likely to behave in a manner that is consistent withother individuals. In that case, bikers could have a feeling of safety among the large riding crowd and have fewer moral pressures to offset the characteristic of slower speed of bikes.

\section{Support partly for the demographic and riding characteristics variables}

It is interesting to note that demographic variables such as gender, age, etc. and riding variables such as riding frequency and experience, etc. generally failed toadd to the predicting intentions. This is not surprising for that age tends to be an insignificant predictor in both scenarios, even if previous works have documented a clear contribution of age and sex to predicting intentions. This is because dividing group about age variable is not involvedin this research that result in the unobvious distribution of age. Gender variable does not emerge as the important predictor which is in line with the studydiscussion[9, 10].The variableof independent children emerges as a significant predictor in e-bikes scenario. This simple correlation relationship is also demonstrated in another scenario.

\section{CONCLUSIONS}

In the present study, intentions toaberrant roadcrossing in e-bikes and bikes scenarios are examined and analyzed using a questionnaire survey basedon the TPB. This research examined the factors of cyclists' intentionsto engage in aberrantcrossing behaviorand established the relationships between demographic, traditional TPB, extended traditional and extended TPB variables, thus came into being the modified TPB model. Then this study had a comparison for the modified model between different situations and impacts of variables were analyzed and compared between e-bikes and bikes scenario.

The result of regression on intention supports the inclusion ofthe traditional variables in both scenarios plus past behavior in bikes, anticipated affect and conformity tendency in e-bikes situation as the significant predictors. All predictor variables accounts for $66 \%$ (e-bikes) and $60 \%$ (bikes) of variance in predicting intentions. On the whole, the results also suggest that three traditional TPB 
variableshas similar effect between two scenarios and they are accounted for over $50 \%$ of all variance in each scenario, however, the addition of traditionalTPB variables resulted in an abundant increase of $42 \%$ variancefor e-bikes scenario than the increase of $36 \%$ variance in another scenario. Then past behavior in bike scenario was able to explain significantlygreater amount of $3 \%$ variance than anticipated affect with $1 \%$ variance in intention of violation, which shows the extended TPB variables are able to mediate the influence brought by traditional TPB variables.

The findings of the present study give strong supports forthe TPB's application to cyclists' intentions to roadcrossing by violating the traffic rules, and it is feasible that the changes of crossing intentions are closely associated withattitudes, subjective norms, PBC and anticipated affect or past behavior. Therefore those components focused could make cyclist's safetyinterventionsmost effective rather than simply test theirutility of model. Based on the results of study, interventions and educationsmeasures in orderto change intention in different situations should be carried out as follows. The strategies are that (1) making most e-bikers know the speed limit and expected maximum speed of e-bikes regulated by law in urban area to prevent cyclists more anticipated intention of aberrant road crossing (2) focusing on conformity tendency for bikes situations, it couldbe conductive to educate young cyclists to know that conformity tendency by violating the traffic rules may leads to risky behaviors (3) making bikers to control the effect brought by past behavior by means of safetyinterventions and educations.

Thus the present findings would indicate a good level of predictionof intentions across scenarios. Furthermore, there are also a number of works needed to the future researches: (1) to constructTPB models in two situations could be focused on observing actual behavior; (2) more qualitative questionnaires should be surveyed and analyzed to enrich TPB model; (3) the powerof extended variables to influencetraditional TPB in modified model needs to be tested in this riding domain.

\section{ACKNOWLEDGMENT}

This research was supported by National Natural Science Foundation of China (No.51278103).

\section{REFERENCES}

[1] Cherry, C. (2007) Electric Bike Use in China and Their Impacts on Environment, Safety, Mobility and Accessibility. ITS Working Paper UCB-ITS-VWP-2007-3.

[2] Cherry, C., Weinert,J., Yang, X., 2009. Comparative environmental impacts of electric bikes in China. Transportation Research Part D 14, 281-290.

[3] CRTASR, 2010. China Road Traffic Accidents Statistics Report. Traffic Administration Bureau of China State Security Ministry, Beijing.

[4] Bai, L., Liu, P., Chen Y., Zhang, X., Wang, W. Comparative analysis of the safety effects of electric bikesat signalized intersections. Transportation Research Part D 20 (2013) 48-54.

[5] Wang, M. The characteristic analysis of electric bikes' traffic safety in urban road. Master Dissertation, Beijing City, IA:Beijing Jiaotong University, 2011.

[6] Taylor, D. and W.J. Davis. Review of Basic Research in Bicycle Traffic Science, 13 Traffic Operations, and Facility Design.
Transportation Research Record 1674, 14 TRB, National Research Council, Washington, D.C., pp. 102-110, 1999.

[7] Yao, L.,Wu, C., 2012. Traffic safety of e-bike cyclists in China: safety attitudes, risk perception, and aberrant riding behaviors. Transportation Research Board, 4599.

[8] Ajzen, I., 1985. From intentions to actions: a theory of planned behavior. In: Kuhl,J., Beckman, J. (Eds.), Action Control: From Cognition to Behavior. Springer, Heidelberg, Germany, pp. 11-39.

[9] Chorlton, K., Mark, C., Samantha, J.. Identifying the psychological determinants of risky riding:An application of an extended Theory of Planned Behaviour. Accident Analysis and Prevention 49 (2012) 142-153.

[10] Zhou, R.,William J. Horrey, Yu,R.. The effect of conformity tendency on pedestrians' road-crossing intentions inChina: An application of the theory of planned behavior. Accident Analysis and Prevention 41 (2009) 491-497.

[11] Conner, M., Sparks, P., 2005. Theory of planned behaviour and health behaviour.In: Conner, M., Norman, P. (Eds.), Predicting Health Behaviour., 2nd ed. OpenUniversity Press, Maidenhead, pp. 170-222.

[12] Díaz, E.M., 2002. Theory of planned behavior and pedestrians' intentions to violatetraffic regulations. Transportation Research Part F 5, 169-175.

[13] Mortimer, R., 1984. Evaluation of the motorcycling riding course. Accident Analysisand Prevention 16 (1), 63-71.

[14] Conner, M., Smith, N., McMillan, B.,2003. Examining normative pressure in the theoryof planned behaviour: impact of gender and passengers on intentions tobreak the speed limit. Current Psychology 22 (3), 252-263.

[15] Conner, M., Lawton, R., Parker, D., Chorlton, K., Manstead, A.S. Stradling, S., 2007.Application of the theory of planned behavior to the prediction of objectivelyassessed breaking of posted speed limits. British Journal of Psychology 98 (3),429-453.

[16] McEachan, R.R.C., Conner, M., Taylor, N.J., Lawton, R.J., 2011. Prospective predictionof health-related behaviors with the theory of planned behavior: a metaanalysis.Health Psychology Review, doi: 10.1080/17437199.2010.521684.

[17] Evans, D., Norman, P., 2003. Predicting adolescent pedestrians'road-crossing intentions:an application and extension of the Theory of Planned Behaviour. HealthEducation Research 18, 267-277.

[18] Shankar, U., 2001. Recent Trends in Fatal Motorcycle Crashes (DOT HS 809 271).National Highway Traffic Road Safety Administration, Washington, DC.

[19] Cherry, C.R. and R. Cervero. Use Characteristics and Mode Choice Behavior of 5 Electric Bikes in China. Working Paper, UCB-ITS-VWP-2006-5, 2006

[20] Hou, W., 2009. The research of customer loyalty based on structural equation model (SEM)-a fast-moving consumer goods industry asa example [D]. China University Of Petroleum, 2009.

[21] Nunnally, J., Psychometric Theory, New York: McGraw-hill, 1978.

[22] Lin, S., He, M., He, M. et al., Comparison Study on Operating Speeds of ElectricBicycles and Bicycles: Experience from Field Investigation in Kunming, China,Transportation Research Record: Journal of the Transportation Research Board, Vol.2048, 2008, pp. 52-59.

[23] Weinstein, N.D., Klein, W., 1996. Unrealistic optimism: present and future.Journalof Social and Clinical Psychology 15, 1-8. 